\title{
Prognostic Significance of Clinical and Post- Neoadjuvant Chemotherapy Associated Histomorphological Parameters in Osteosarcoma: A Retrospective Study from a Tertiary Care Center
}

\author{
Navatha Vangala ${ }^{1}$ Shantveer G. Uppin ${ }^{1}$ \\ Sadashivudu Gundeti ${ }^{3}$ (1) \\ ${ }^{1}$ Department of Pathology, Nizams Institute of Medical Sciences, \\ Hyderabad, Telangana, India \\ 2 Department of Orthopaedics, Nizams Institute of Medical Sciences, \\ Hyderabad, Telangana, India \\ ${ }^{3}$ Department of Medical Oncology, Nizams Institute of Medical \\ Sciences, Hyderabad, Telangana, India
}

\author{
Address for correspondence Shantveer G. Uppin, MD (Pathology), \\ Department of Pathology, Nizams Institute of Medical Sciences, \\ Hyderabad, Telangana 500082, India \\ (e-mail: drsguppin@yahoo.co.in).
}

Ind J Med Paediatr Oncol 2021;42:547-553.

\begin{abstract}
Keywords

- osteosarcoma

- Huvos and Rosen grade

- integrated prognostic index

Introduction Osteosarcoma is the most prevalent bone cancer in adolescents. Neoadjuvant chemotherapy (NACT) followed by resection is the current modality of treatment for osteosarcoma. Histological evaluation of extent of tumor necrosis on resection is a well-established prognostic indicator in osteosarcoma correlating with survival in most cases.

Objectives The main objective of this study was to establish prognostic significance of various clinical and histological parameters post-NACT in osteosarcoma and to compare the integrated prognostic index proposed by Chui et al, with grading of response to NACT by Huvos and Rosen for osteosarcoma.

Materials and Methods This is a retrospective study done over a period of four years and includes 47 cases of osteosarcoma treated with NACT. All slides were reviewed and association of various clinical and histological parameters with overall survival was assessed with chi-squared test and Cox-regression analysis.

Results Statistical analysis revealed the prognostic significance of age at presentation, anatomic site, primary tumor size, metastatic status, and clinical stage. Histological parameters such as mitosis $\geq 10 / 10 \mathrm{hpfs}, \geq 10 \%$ residual tumor were significantly associated with poor survival. Tumor necrosis $\geq 90 \%$ (excluding areas of hemorrhage, fibrosis and acellular osteoid) was significantly associated with increased survival. An integrated prognostic index formed by combining above parameters gives a better estimate of overall survival compared with residual disease or necrosis alone.

Conclusion Integrated prognostic index improves prognostication in patients treated for osteosarcoma.
\end{abstract}

DOI https://doi.org/ 10.1055/s-0041-1740113. ISSN 0971-5851.
(C) 2021. Indian Society of Medical and Paediatric Oncology. All rights reserved.

This is an open access article published by Thieme under the terms of the Creative Commons Attribution-NonDerivative-NonCommercial-License, permitting copying and reproduction so long as the original work is given appropriate credit. Contents may not be used for commercial purposes, or adapted, remixed, transformed or built upon. (https://creativecommons.org/ licenses/by-nc-nd/4.0/)

Thieme Medical and Scientific Publishers Pvt. Ltd., A-12, 2nd Floor, Sector 2, Noida-201301 UP, India 


\section{Introduction}

Osteosarcoma is the most prevalent bone cancer in adolescents. Current modality of treatment is neoadjuvant chemotherapy (NACT) followed by surgical ablation. Traditionally, only post-chemotherapy necrosis is considered the best prognostic parameter. In addition to tumor necrosis, chemotherapy induces variable histological alterations. These changes along with various clinical parameters are of prognostic significance and an essential component for treatment stratification. The present study aims to establish prognostic significance of these parameters and also to compare integrated prognostic index proposed by Chui et al, ${ }^{1}$ with grading of response to NACT by Huvos and Rosen, ${ }^{2}$ and residual disease alone.

\section{Materials and Methods}

This is a retrospective study done between January 2015 and December 2018 during which 50 cases of osteosarcoma were resected at our institute which is a tertiary hospital. All cases ( $n=47$ ) of high-grade conventional osteosarcoma and telangiectatic osteosarcomas with preoperative NACT were included in the study. The study was designed to assess the significance of clinical and morphological features as independent (primary outcome) prognostic factors as well as in combination (secondary outcome) in treated cases of osteosarcoma. Cases diagnosed as paraosteal osteosarcomas $(n=3)$ were treated with only resection and were excluded. Clinical, gross findings were collected, microscopic findings were reviewed, and chemotherapy response was assessed for each case.

\section{Presurgical Treatment}

All the cases were treated as per the standard osteosarcoma treatment protocol. ${ }^{3-8}$ Cases with localized disease were treated preoperatively with two cycles of Adriamycin and cisplatin followed by resection of the lesion. This was followed by four cycles of chemotherapy post-surgery. Cases with metastatic disease at presentation received four to six cycles of the above said chemotherapeutic agents upfront followed by resection of primary if possible. Since our intent of treatment is cure, dose intensity was maintained with appropriate supportive care (cisplatin $60 \mathrm{mg} / \mathrm{m}^{2} \mathrm{D} 1$ \& D2 and Adriamycin $37.5 \mathrm{mg} / \mathrm{m}^{2}$ D1 \& D2 every 21 days).

The following clinical and morphological data was collected.

\section{Clinical Data}

Age, sex, presence or absence of metastasis, clinical stage, tumor location.

\section{Grossing}

A full-face longitudinal section/flap of $\sim 0.3$ to $0.4 \mathrm{~cm}$ in thickness is taken that displays the greatest extent of tumor as well as any cortical defects. Entire longitudinal section is submitted mapping the tumor with a minimum of one block per centimeter of the tumor. Areas that represent intra- tumoral heterogeneity are additionally sampled and a minimum of 30 sections of resected tumor were examined microscopically to quantify the tumor response.

\section{Morphological Data}

- Size of the tumor, tumor subtype, involvement of resected margins.

- Presence or absence of lymphovascular invasion, mitosis/ 10hpf.

- Post-chemotherapy changes such as areas of necrosis/ acellular osteoid, fibrosis/ hyalinization, and residual disease were quantified separately by estimating their percentage in the slides with tumor and then mean was calculated based on the number of slides with tumor. In every case, post-chemotherapy response grade as proposed by Huvos and Rosen ${ }^{2}$ and the integrated prognostic index as proposed by Chui et al, ${ }^{1}$ was assessed.

\section{Statistical Analysis}

Overall survival was calculated from date of primary surgery to date of last follow-up or date of death from any cause. Association of clinical and histological parameters with overall survival assessed with chi-squared test and Coxregression analysis using SPSS software, version 26.0 (IBM Corp., Armonk, New York, United States).

\section{Ethics}

The study was approved by the Nizams Institute of Medical Sciences (NIMS), Institutional Ethics Committee with approval number of EC/NIMS/2623/2020 dated December 2, 2020. The procedures followed were in accordance with the ethical standards of the responsible committee on human experimentation (institutional) and with the Helsinki Declaration of 1964, as reviewed in 2013. Consent waiver form was obtained from the Ethics Committee due to the retrospective nature of the study.

\section{Results}

The 47 cases included in the study affected 32 men and 15 women with M: F of 2:1. Centrally located tumors affected relatively older individuals (median: 37 years, range: $20-62$ years) compared with peripherally located ones (median: 17 years, range: 7-44 years.) There was no missing data for any variable included in the study.

Most common presenting complaint was pain with swelling (40/47) (85\%) followed by swelling alone (5/47) (11\%) and $4 \%(2 / 47)$ cases had a history of pathological fracture. All the cases were primary osteosarcoma without any pre-existing bone conditions. The affected sites of these cases are depicted in - Fig. 1. Among peripherally located tumors $(n=41)$, the most common location was distal femur followed by proximal tibia. Among centrally located tumors $(n=6)$, mandible was the most common site. Of these 47 cases, preoperative fine needle aspiration and/or biopsy slides were available for review in 43 cases.

Median size of the tumor at resection was $9 \mathrm{~cm}$ with a range of 2.9 to $21.5 \mathrm{~cm}$. Central tumors were of larger size (median $12 \mathrm{~cm}$ ) compared with peripheral tumor (median 


\section{Central location $(n=6)$}

\section{Extremities (n=41)}
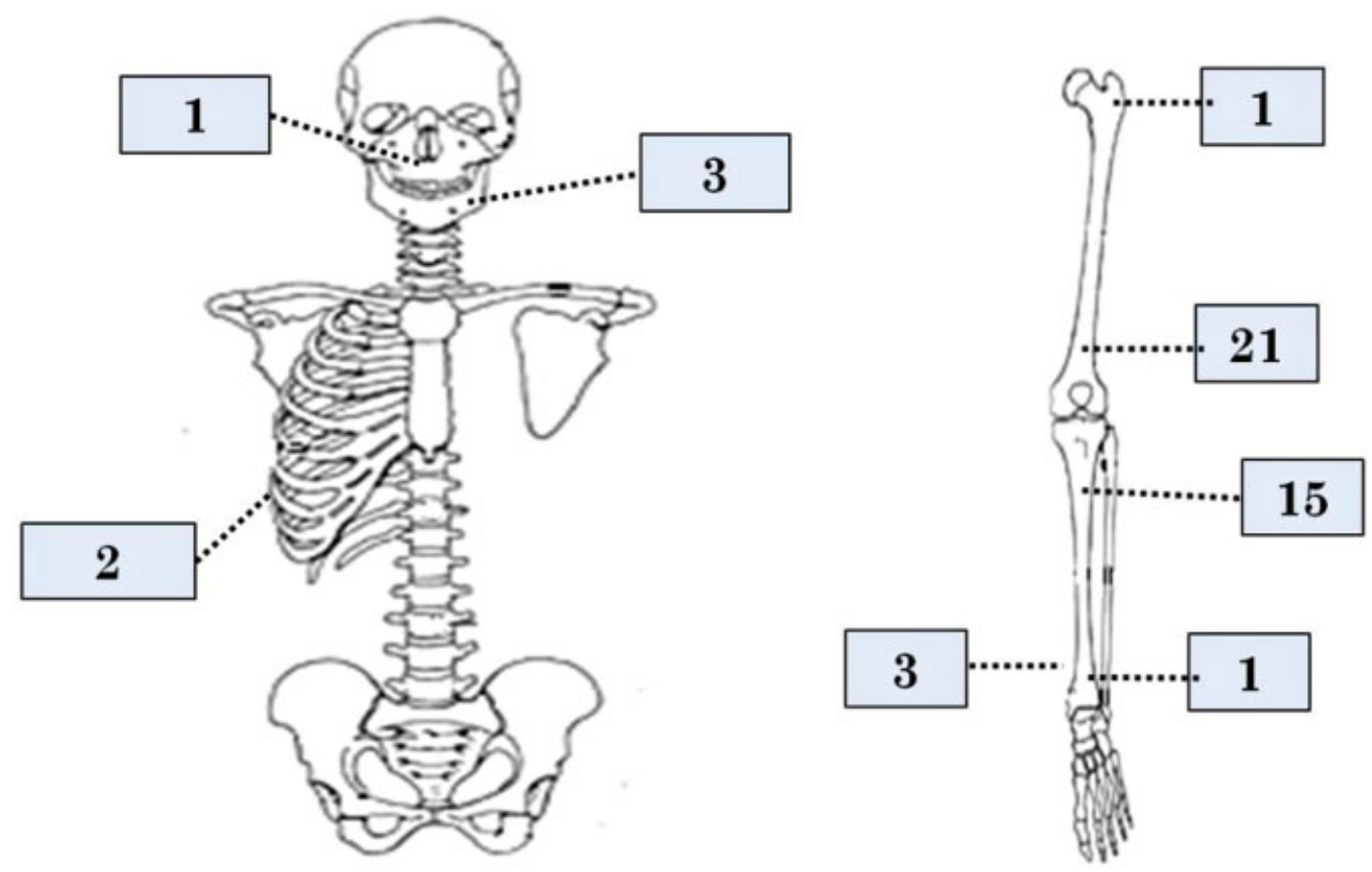

Fig. 1 Pictorial representation of tumor site distribution of osteosarcoma.

$7.3 \mathrm{~cm})$. The former also most often infiltrated overlying skin compared with the later (4/6 cases vs. 2/41 cases).

\section{Histological Findings}

Tumor subtyping was done on both biopsy and resection specimens. The concordance rate between initial diagnosis on biopsy and final diagnosis on resection was very high (92\%). Of the 47 tumors, 42 were conventional osteosarcomas, with 35 of them having osteoblastic and seven chondroblastic morphology. The remaining five were telangiectatic osteosarcomas. Histopathological diagnosis of chondroblastic variant was made based on the predominance of chondroid matrix in the midst of neoplastic cells in $\sim 40$ to $50 \%$ of the entire specimen. Various post-chemotherapy morphological findings listed above were assessed in every case (-Fig. 2). Microscopic involvement of surgical resected margin was noted in $6 / 47$ cases $(12.7 \%)$.

\section{Survival Analysis}

The median duration of follow-up was 3 years with a range from 1 to 5 years. The median overall survival was 16 months with a range of 3 to 56 months. At the last follow-up, 15 patients had died, of which one had developed post-chemotherapy cytopenia with subsequent sepsis, 10 patients had metastasis, 2 had recurrences, and 2 died with the primary disease. Of the 32 patients who were alive at last follow-up, eight cases had metastasis, one had recurrence, and the remaining 23 cases were alive with no evidence of recur- rence or metastatic disease. In total, 18 cases had metastasis of which 10 patients expired and the rest $(n=8)$ were alive at last follow-up. Five of the 18 cases had metastasis at presentation of which two died during the treatment and three were alive at the last follow-up with stable disease. There was no significant difference in overall survival and prognosis in patients with metastasis at presentation when compared with patients with subsequent metastasis.

Prognostic significance of each parameter is assessed in comparison with 1,3 , and 5 year's survival rates based on date of resection and with overall survival irrespective of date of resection. By chi-squared analysis, the clinical parameters (-Table 1), which were significantly associated with increased survival, include age at presentation $<40$ years $(p=0.041)$, male gender $(p=0.05)$, primary tumor size $<8$ $\mathrm{cm}(p=0.035)$, absence of metastases $(p=0.003)$, clinical stages I and II $(p=0.002)$, and tumor located in extremities $(p=0.037)$.

With respect to histological subtypes, all five cases with telangiectatic subtypes were alive at last follow-up. These patients had a favorable prognosis with better overall survival rate $(100 \%$ vs. $64.3, p=0.043)$ in comparison with conventional osteosarcomas. Histological parameters (-Table 2) such as mitosis $\geq 10 / 10$ hpfs ( $p=0.032$ ), $\geq 10 \%$ residual tumor $(p<0.001)$ were significantly associated with poor survival. Tumor necrosis $\geq 90 \%$ ( $p=0.012$ ) was significantly associated with increased survival. On comparison, integrated prognostic index was found to be significantly 


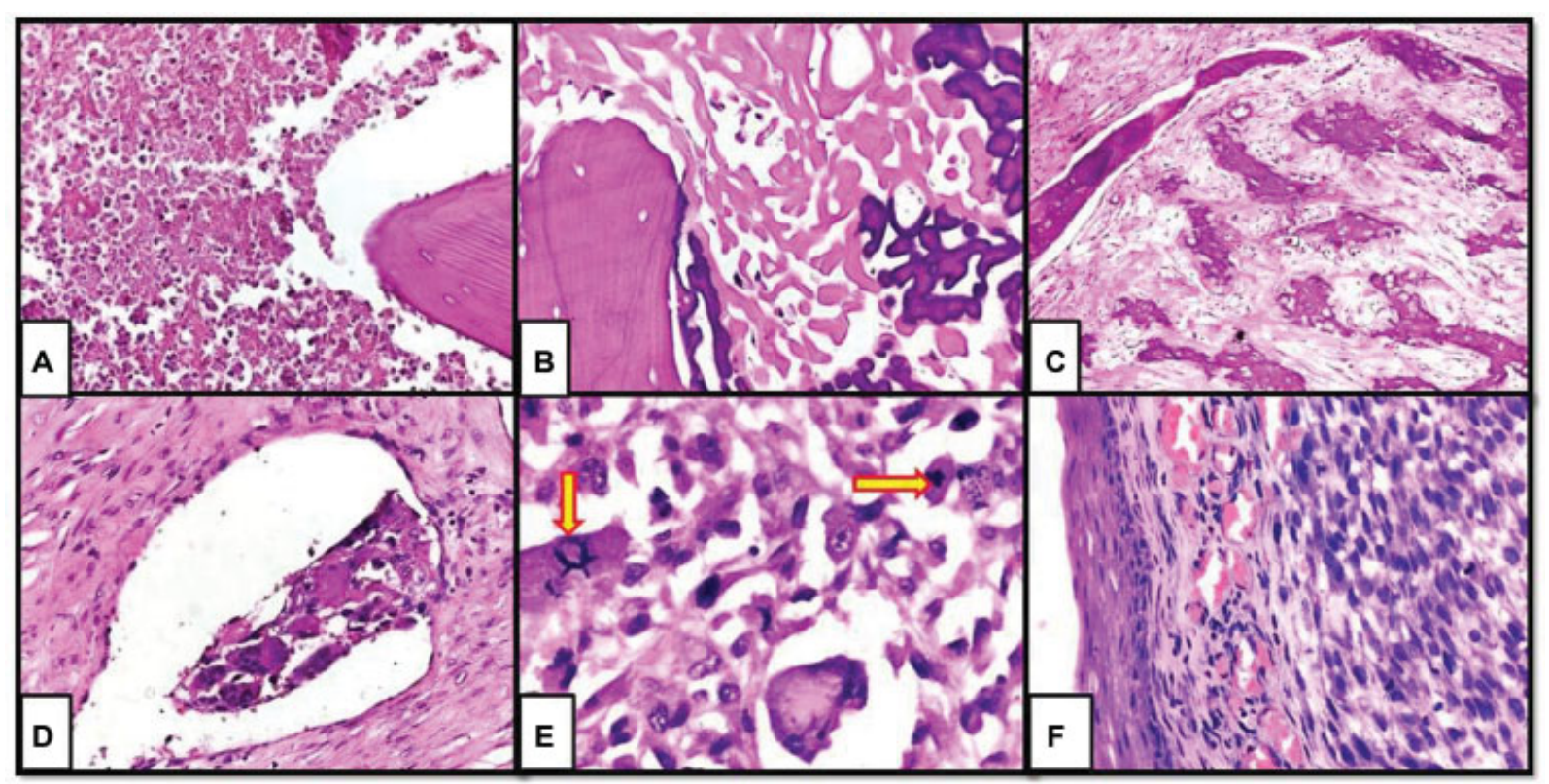

Fig. 2 Post-chemotherapy changes in osteosarcoma. (A) Necrosis, (B) acellular osteoid, (C) fibrosis, (D) lymphovascular invasion, (E) atypical mitosis (arrows), and (F) residual disease with skin involvement ( $\mathrm{x} 400$, hematoxylin and eosin).

better parameter than Huvos and Rosen grades in assessing survival outcome with a $p$-value $<0.001$.

Cox-regression analysis also revealed integrated prognostic index as a significantly better prognostic parameter $(p=0.0360)$ in comparison to Huvos and Rosen grades $(p=0.244)$ and residual disease $(p=0.099)$ alone as depicted in - Table 3. Hazard ratios for Huvos and Rosen grade I and II as well as the moderate and high-risk categories based on prognostic index were high indicating the poor survival outcome.

\section{Discussion}

Osteosarcoma is a primary malignant bone tumor with bimodal age distribution most commonly seen in second and third decades. ${ }^{3}$ It has a predilection for sites with rapid growth and most proliferative growth plates such as in long bones of extremities, especially distal femur (30\%), proximal tibia (15\%), and proximal humerus $(15 \%) .{ }^{4}$ Osteosarcoma is thought to arise from primitive mesenchymal bone-forming cells, and production of malignant osteoid is its histological

Table 1 Statistical analysis by chi-squared test to assess the prognostic significance of various clinical parameters in osteosarcoma

\begin{tabular}{|c|c|c|c|c|c|c|c|c|c|}
\hline \multicolumn{2}{|c|}{ Chi-squared analysis } & \multicolumn{2}{|c|}{$\begin{array}{l}1 \text { years survival } \\
(n=47)\end{array}$} & \multicolumn{2}{|c|}{$\begin{array}{l}3 \text { years survival } \\
(n=20)\end{array}$} & \multicolumn{2}{|c|}{$\begin{array}{l}5 \text { years survival } \\
(n=13)\end{array}$} & \multicolumn{2}{|c|}{ Overall survival } \\
\hline \multicolumn{2}{|l|}{ Parameter } & $\%$ & $p$-Value ${ }^{a}$ & $\%$ & $p$-Value & $\%$ & $p$-Value & $\%$ & $p$-Value \\
\hline \multirow[t]{2}{*}{ Age (in years) } & $<40$ & 83 & \multirow[t]{2}{*}{0.363} & 81 & \multirow[t]{2}{*}{0.028} & 80 & \multirow[t]{2}{*}{0.125} & 74 & \multirow[t]{2}{*}{0.041} \\
\hline & $>40$ & 100 & & 25 & & 33 & & 25 & \\
\hline \multirow[t]{2}{*}{ Sex } & Women & 77 & \multirow[t]{2}{*}{0.297} & 56 & \multirow[t]{2}{*}{0.202} & 60 & \multirow[t]{2}{*}{0.569} & 53 & \multirow[t]{2}{*}{0.05} \\
\hline & Men & 88 & & 82 & & 75 & & 79 & \\
\hline \multirow[t]{2}{*}{ Size $(\mathrm{cm})$} & $\leq 8(\mathrm{~T} 1)$ & 89 & \multirow[t]{2}{*}{0.115} & 100 & \multirow[t]{2}{*}{0.001} & 86 & \multirow[t]{2}{*}{0.164} & 82 & 0.035 \\
\hline & $>8(\mathrm{~T} 2)$ & 77 & & 33 & & 50 & & 55 & \\
\hline \multirow[t]{2}{*}{ Metastasis } & Absent & 91 & \multirow[t]{2}{*}{0.088} & 73 & \multirow[t]{2}{*}{0.573} & 90 & \multirow[t]{2}{*}{0.003} & 84 & \multirow[t]{2}{*}{0.003} \\
\hline & Present & 72 & & 60 & & 0 & & 44 & \\
\hline \multirow[t]{4}{*}{ Clinical stage } & IA & 100 & \multirow[t]{4}{*}{0.094} & 100 & \multirow[t]{4}{*}{0.015} & 100 & \multirow[t]{4}{*}{0.014} & 100 & \multirow[t]{4}{*}{0.002} \\
\hline & IIA & 100 & & 100 & & 100 & & 100 & \\
\hline & IIB & 75 & & 20 & & 50 & & 58 & \\
\hline & III/IV & 72 & & 60 & & 0 & & 44 & \\
\hline \multirow[t]{2}{*}{ Tumor location } & Extremities & 86.4 & \multirow[t]{2}{*}{0.002} & 81 & \multirow[t]{2}{*}{0.028} & 73 & \multirow[t]{2}{*}{0.522} & 75 & \multirow[t]{2}{*}{0.037} \\
\hline & Head and trunk & 33.3 & & 25 & & 50 & & 33 & \\
\hline
\end{tabular}

${ }^{a} p$-Value of significance. 
Table 2 Statistical analysis by chi-squared test to assess the prognostic significance of various morphological parameters in osteosarcoma

\begin{tabular}{|c|c|c|c|c|c|c|c|c|c|}
\hline \multirow{2}{*}{\multicolumn{2}{|c|}{$\begin{array}{l}\text { Chi-squared analysis } \\
\text { Parameter }\end{array}$}} & \multicolumn{2}{|c|}{$\begin{array}{l}1 \text { year survival } \\
(n=47)\end{array}$} & \multicolumn{2}{|c|}{$\begin{array}{l}3 \text { years survival } \\
(n=20)\end{array}$} & \multicolumn{2}{|c|}{$\begin{array}{l}5 \text { years survival } \\
(n=13)\end{array}$} & \multicolumn{2}{|c|}{ Overall survival } \\
\hline & & $\%$ & $p$-Value ${ }^{a}$ & $\%$ & $p$-Value & $\%$ & $p$-Value & $\%$ & $p$-Value \\
\hline \multirow[t]{3}{*}{ Mitosis /10high power fields } & $0-9$ & 92 & \multirow[t]{3}{*}{0.02} & 77 & \multirow[t]{3}{*}{0.264} & 86 & \multirow[t]{3}{*}{0.188} & 81 & \multirow[t]{3}{*}{0.032} \\
\hline & $10-19$ & 58 & & 67 & & 60 & & 42 & \\
\hline & $\geq 20$ & 100 & & 0 & & 0 & & 50 & \\
\hline \multirow[t]{2}{*}{ Necrosis } & $<50 \%$ & 73 & \multirow[t]{2}{*}{0.012} & 58 & \multirow[t]{2}{*}{0.163} & 57 & \multirow[t]{2}{*}{0.308} & 57 & \multirow[t]{2}{*}{0.012} \\
\hline & $\geq 50 \%$ & 100 & & 88 & & 83 & & 90 & \\
\hline \multirow[t]{3}{*}{ Residual disease } & $<10 \%$ & 100 & \multirow[t]{3}{*}{0.012} & 100 & \multirow[t]{3}{*}{0.012} & 100 & \multirow[t]{3}{*}{0.206} & 100 & \multirow[t]{3}{*}{0.001} \\
\hline & $10-49 \%$ & 88 & & 78 & & 72 & & 71 & \\
\hline & $\geq 50 \%$ & 58 & & 20 & & 33 & & 33 & \\
\hline \multirow[t]{4}{*}{ Huvos and Rosen score } & 1 & 71 & \multirow[t]{4}{*}{0.205} & 50 & \multirow[t]{4}{*}{0.040} & 50 & \multirow[t]{4}{*}{0.359} & 52 & \multirow[t]{4}{*}{0.084} \\
\hline & 2 & 91 & & 14 & & 83 & & 72 & \\
\hline & 3 & 100 & & 100 & & 100 & & 100 & \\
\hline & 4 & 100 & & - & & - & & 100 & \\
\hline \multirow[t]{3}{*}{ Integrated prognostic index } & $0.1^{\mathrm{b}}$ & 95 & \multirow[t]{3}{*}{0.0001} & 100 & \multirow[t]{3}{*}{1.002} & 100 & \multirow[t]{3}{*}{0.043} & 90 & \multirow[t]{3}{*}{0.0001} \\
\hline & $2.3^{c}$ & 95 & & 75 & & 71 & & 75 & \\
\hline & $4.5^{d}$ & 40 & & 0 & & 0 & & 20 & \\
\hline
\end{tabular}

${ }^{a} p$-Value of significance, ${ }^{b}(0.1)$, low risk, ${ }^{c}(2.3)$, intermediate risk), ${ }^{d}(4.5)$ high risk.

Table 3 Multivariate Cox-regression analysis to compare prognostic significance of Huvos and Rosen grades, residual disease with integrated prognostic index in osteosarcoma

\begin{tabular}{|c|c|c|c|c|c|c|c|c|c|c|}
\hline \multirow{2}{*}{\multicolumn{2}{|c|}{$\begin{array}{l}\text { Cox-regression analysis } \\
\text { Parameter }\end{array}$}} & \multicolumn{3}{|c|}{1 years survival $(n=47)$} & \multicolumn{3}{|c|}{3 years survival $(n=20)$} & \multicolumn{3}{|c|}{5 years survival $(n=13)$} \\
\hline & & \multirow{2}{*}{$\frac{\mathrm{HR}^{\mathrm{a}}}{6.55}$} & \multirow{2}{*}{$\begin{array}{l}95 \% \mathrm{Cl}^{\mathrm{b}} \\
1.9-2.3\end{array}$} & \multirow{5}{*}{$\frac{p \text {-Value }}{0}$} & \multirow{2}{*}{$\begin{array}{l}\mathrm{HR} \\
4.2\end{array}$} & \multirow{2}{*}{$\begin{array}{l}(95 \% \mathrm{CI}) \\
1.2-14.4\end{array}$} & \multirow{2}{*}{$\begin{array}{l}p \text {-Value } \\
0.108\end{array}$} & \multirow{2}{*}{$\begin{array}{l}\mathrm{HR} \\
2.2\end{array}$} & \multirow{2}{*}{$\begin{array}{l}95 \% \mathrm{Cl} \\
1.3-8.16\end{array}$} & \multirow{2}{*}{$\begin{array}{l}p \text {-Value } \\
0.244\end{array}$} \\
\hline Huvos and Rosen grade & 1 & & & & & & & & & \\
\hline & 2 & 2.45 & $1.25-4.68$ & & 2.86 & $1.23-5.25$ & & 2.12 & $1.35-6.14$ & \\
\hline & 3 & 1.65 & $0.96-2.78$ & & 1.15 & $0.92-3.1$ & & 1.53 & $0.94-2.18$ & \\
\hline & 4 & 1 & - & & 1.12 & $0.85-2.3$ & & 1.09 & $0.83-2.5$ & \\
\hline \multirow[t]{2}{*}{ Residual disease (\%) } & $<10$ & 1 & - & \multirow[t]{2}{*}{0.012} & 1 & - & \multirow[t]{2}{*}{0.019} & 1.5 & $0.93-3.6$ & \multirow[t]{2}{*}{0.099} \\
\hline & $\geq 10$ & 5 & $1.4-12.4$ & & 6 & $1.3-16$ & & 4.2 & $1.2-12$ & \\
\hline \multirow{3}{*}{$\begin{array}{l}\text { Integrated prognostic } \\
\text { index }\end{array}$} & 0.1 & 1 & - & \multirow[t]{3}{*}{0.003} & 1 & - & \multirow[t]{3}{*}{0.003} & 1 & - & \multirow[t]{3}{*}{0.036} \\
\hline & 2.3 & 3.2 & $1.6-5.6$ & & 2.6 & $1.3-5.8$ & & 2.05 & $1.3-4.2$ & \\
\hline & 4.5 & 6.55 & $1.9-22.3$ & & 5.2 & $2.2-27$ & & 4.6 & $1.2-18$ & \\
\hline
\end{tabular}

${ }^{\mathrm{a}} \mathrm{HR}$, hazard ratio, ${ }^{\mathrm{b}} \mathrm{Cl}$, confidence interval, ${ }^{c} \mathrm{p}$-Value of significance.

hallmark. Most commonly, patients die of pulmonary metastatic disease. The current modality of treatment is NACT followed by surgical ablation. ${ }^{5,6}$ Review of literature shows very few studies that explored the prognostic significance of various clinical and histological attributes postchemotherapy.

Traditional chemotherapy response scoring system is based on tumor necrosis that was devised by Huvos and Rosen et al in 1982. ${ }^{2}$ They assessed the histological effect of preoperative chemotherapy on the resected primary tumor and devised a grading system to assess the extent of tumor destruction. The grades devised were as follows: little or no evidence of necrosis (grade I), 50-90\% necrosis among histologically viable tumor areas (grade II), predominant necrosis of $90-99 \%$ with scattered sites of viable tumor (grade III), and no histological evidence of viable tumor with 100\% necrosis (grade IV). The chemotherapy effect was determined after examining a minimum of 30 representative sections from the resected specimen. Their study concluded that grade III and IV response was significantly 
associated with increased disease-free survival and all cases of relapses showed a response of grade I or II. ${ }^{2}$

Raymond et al in their study also emphasized the prognostic significance of post-chemotherapy tumor necrosis along with other clinical and morphologic attributes such as age, sex, tumor size, tumor site, and subtype. ${ }^{5}$ Similar results were seen in studies by Bacci et al, Harting et al, and Pakos et al. ${ }^{9-11}$ Chui et al's study also highlighted the prognostic significance of clinical parameters such as tumor size, metastatic status, clinical stage, and tumor site. ${ }^{1}$ Similar to these studies, the present study also revealed that age at presentation $<40$ years, male gender, tumor located in extremities, primary tumor size $<8 \mathrm{~cm}$, absence of metastasis at presentation, and clinical stage I and II were significantly associated with increased overall survival. There was no significant difference in the overall survival for the two cases that had a history of pathological fracture $(p=0.46)$.

Picci et al's study particularly stressed on local recurrence in osteosarcoma in relation to histopathologic findings such as involvement of resected margins and development of a pseudocapsule around tumor. ${ }^{12} \mathrm{~A}$ mature pseudocapsule around the tumor was not seen in cases who have not received chemotherapy or who had a poor response to it. In contrast, a well-formed, avascular, collagenous capsule was seen in patients with good response ( $>90 \%$ necrosis) to chemotherapy and this was presumably related to growth arrest following therapy that resulted in sufficient time to develop a capsule. In the present study, six out of 47 cases ( $12.7 \%$ cases) showed tumor at surgical resection margins on microscopy of which three cases are deceased and two had recurrence. When compared with margin negative cases, there was no significant difference in the overall survival and prognosis $(p=0.192)$.

The present study revealed that among cases of osteosarcoma treated with chemotherapy, telangiectatic osteosarcomas had a favorable prognosis when compared with other subtypes of conventional osteosarcomas $(p=0.043)$. This was in line with findings of several others studies. ${ }^{1,13-16}$ Bentzen et al stated that among conventional osteosarcomas, fibroblastic tumors had better prognosis compared with osteoblastic and chondroblastic subtypes. ${ }^{17}$

Although, most centers use tumor necrosis as the parameter for scoring chemotherapy response, it did not translate into survival benefit in many studies. ${ }^{18-20}$ The possible explanation for this could be that, in tumors with necrosis $<90 \%$, major problem lies in distinguishing necrosis from other noncellular elements such as areas of hemorrhage, fibrosis, and acellular osteoid thereby leading to erroneous quantification of tumor necrosis and residual tumor. Acellular osteoid is one of the major secondary changes seen postchemotherapy and was seen in $58 \%$ of our cases but was not associated with significant overall survival $(p=0.085)$. To address such issues, Chui et al devised an integrated prognostic index combining various clinical and morphologic attributes for effective stratification of patients post-chemotherapy. ${ }^{1}$ This index enabled further stratification of cases into low, intermediate, and high-risk categories based on the final score. In our study, hazard ratios for Huvos and Rosen grade I and II as well as the moderate- and high-risk categories based on prognostic index were high indicating the poor survival outcome similar to their study. This new scoring system needs to be applied to larger datasets and further validation is needed.

As per Chui et al, ${ }^{1}$ residual tumor is more reliable parameter over tumor necrosis for effective stratification of patients post-chemotherapy. When parameters of integrated prognostic index were analyzed separately, tumor size $(p=0.035)$, tumor location $(p=0.037)$, mitotic rate $(0.032)$, and residual viable tumor $(p=0.001)$ retained significance as independent prognostic factors except for lymphovascular invasion $(p=0.42)$.

The present study demonstrated that post-NACT in osteosarcoma, $>50 \%$ necrosis $(p=0.012),<10 \%$ residual disease $(p=0.001)$, and integrated prognostic index with low risk $(p<0.0001)$ were significantly associated with overall survival and of these, the integrated prognostic index had a slightly higher statistical significance. Several other studies also have emphasized on the percentage of residual or viable tumor post-chemotherapy as the significant prognostic parameter when compared with percentage of necrosis. ${ }^{21-23}$ Mitoses $\geq 10 / 10$ hpfs are associated with poor survival as reported by some others. ${ }^{24,25}$ Some studies have highlighted post-chemotherapy changes such as coagulative necrosis, fibrosis/hyalinization, vascular enrichment, edematous stro$\mathrm{ma}$, and bizarre giant cells with degenerative features. ${ }^{26-28}$ We encountered bizarre tumor giant cells in $44 \%$ cases.

\section{Limitations of the Study}

1. The study is limited in terms of the sample size; however, the number of cases studied were comparatively higher than other similar studies.

2. This study has short follow-up. The future research direction is to extend the study with longer follow-up, for an additional 10 to 15 years.

\section{Conclusion}

Studies exploring the prognostic significance of various morphologic features in post-chemotherapy osteosarcoma are very few. Systematic statistical analysis in the present study revealed that age at presentation, anatomic site, primary tumor size, metastatic status, and clinical stage are parameters of prognostic significance. Necrosis ( $>50 \%$ ), residual disease $(<10 \%)$, and integrated prognostic index with low risk were significantly associated with overall survival and of these, the integrated prognostic index had a slightly higher statistical significance.

\section{Authors' Contribution}

Navatha Vangala and Shantveer G. Uppin were involved in concepts, design, definition of intellectual content, literature search, data acquisition, data analysis, statistical analysis, manuscript preparation, editing, and review. K. Nageshwara Rao, P. Chandrasekhar, and Sadashivudu Gundeti were involved in concepts, definition of 
intellectual content, literature search, data acquisition, data analysis, manuscript preparation, editing, and review. Navatha Vangala and Shantveer G. Uppin have provided guarantee to this manuscript.

\section{Funding}

Nil

\section{Conflicts of Interest}

The authors declare no conflicts of interest.

\section{Acknowledgments}

None

\section{References}

1 Chui MH, Kandel RA, Wong M, et al. Histopathologic features of prognostic significance in high-grade osteosarcoma. Arch Pathol Lab Med 2016;140(11):1231-1242

2 Rosen G, Caparros B, Huvos AG, et al. Preoperative chemotherapy for osteogenic sarcoma: selection of postoperative adjuvant chemotherapy based on the response of the primary tumor to preoperative chemotherapy. Cancer 1982;49(06):1221-1230

3 Ottaviani G, Jaffe N. The epidemiology of osteosarcoma. Cancer Treat Res 2009;152:3-13

4 Savage SA, Mirabello L. Using epidemiology and genomics to understand osteosarcoma etiology. Sarcoma 2011;2011:548151

5 Raymond AK, Chawla SP, Carrasco CH, et al. Osteosarcoma chemotherapy effect: a prognostic factor. Semin Diagn Pathol 1987;4 (03):212-236

6 Kim SY, Helman LJ. Strategies to explore new approaches in the investigation and treatment of osteosarcoma. Cancer Treat Res 2009; 152:517-528

7 Bacci G, Picci P, Ferrari S, et al. Primary chemotherapy and delayed surgery for nonmetastatic osteosarcoma of the extremities. Results in 164 patients preoperatively treated with high doses of methotrexate followed by cisplatin and doxorubicin. Cancer 1993;72(11):3227-3238

8 Rosen G, Huvos AG, Mosende C, et al. Chemotherapy and thoracotomy for metastatic osteogenic sarcoma. A model for adjuvant chemotherapy and the rationale for the timing of thoracic surgery. Cancer 1978;41:841-849

9 Bacci G, Longhi A, Versari M, Mercuri M, Briccoli A, Picci P. Prognostic factors for osteosarcoma of the extremity treated with neoadjuvant chemotherapy: 15-year experience in 789 patients treated at a single institution. Cancer 2006;106(05): 1154-1161

10 Harting MT, Lally KP, Andrassy RJ, et al. Age as a prognostic factor for patients with osteosarcoma: an analysis of 438 patients. J Cancer Res Clin Oncol 2010;136(04):561-570

11 Pakos EE, Nearchou AD, Grimer RJ, et al. Prognostic factors and outcomes for osteosarcoma: an international collaboration. Eur J Cancer 2009;45(13):2367-2375

12 Picci P, Sangiorgi L, Rougraff BT, Neff JR, Casadei R, Campanacci M. Relationship of chemotherapy-induced necrosis and surgical margins to local recurrence in osteosarcoma. J Clin Oncol 1994; 12(12):2699-2705

13 Bacci G, Balladelli A, Palmerini E, et al. Neoadjuvant chemotherapy for osteosarcoma of the extremities in preadolescent patients: the Rizzoli Institute experience. J Pediatr Hematol Oncol 2008;30 (12):908-912

14 Bacci G, Mercuri M, Longhi A, et al. Grade of chemotherapyinduced necrosis as a predictor of local and systemic control in 881 patients with non-metastatic osteosarcoma of the extremities treated with neoadjuvant chemotherapy in a single institution. Eur J Cancer 2005;41(14):2079-2085

15 Hauben EI, Weeden S, Pringle J, Van Marck EA, Hogendoorn PC. Does the histological subtype of high-grade central osteosarcoma influence the response to treatment with chemotherapy and does it affect overall survival? A study on 570 patients of two consecutive trials of the European Osteosarcoma Intergroup. Eur J Cancer 2002;38(09):1218-1225

16 McTiernan A, Jinks RC, Sydes MR, et al. Presence of chemotherapyinduced toxicity predicts improved survival in patients with localised extremity osteosarcoma treated with doxorubicin and cisplatin: a report from the European Osteosarcoma Intergroup. Eur J Cancer 2012;48(05):703-712

17 Bentzen SM, Poulsen HS, Kaae S, et al. Prognostic factors in osteosarcomas. A regression analysis. Cancer 1988;62(01): 194-202

18 Zalupski MM, Rankin C, Ryan JR, et al. Adjuvant therapy of osteosarcoma-a Phase II trial: Southwest Oncology Group study 9139. Cancer 2004;100(04):818-825

19 Xing D, Qasem SA, Owusu K, Zhang K, Siegal GP, Wei S. Changing prognostic factors in osteosarcoma: analysis of 381 cases from two institutions. Hum Pathol 2014;45(08):1688-1696

20 Lewis IJ, Nooij MA, Whelan J, et al; MRC BO06 and EORTC 80931 collaborators European Osteosarcoma Intergroup. Improvement in histologic response but not survival in osteosarcoma patients treated with intensified chemotherapy: a randomized phase III trial of the European Osteosarcoma Intergroup. J Natl Cancer Inst 2007;99(02):112-128

21 Bielack SS, Kempf-Bielack B, Delling G, et al. Prognostic factors in high-grade osteosarcoma of the extremities or trunk: an analysis of 1,702 patients treated on neoadjuvant cooperative osteosarcoma study group protocols. J Clin Oncol 2002;20(03): 776-790

22 Whelan JS, Jinks RC, McTiernan A, et al. Survival from high-grade localised extremity osteosarcoma: combined results and prognostic factors from three European Osteosarcoma Intergroup randomised controlled trials. Ann Oncol 2012;23(06):1607-1616

23 Glasser DB, Lane JM, Huvos AG, Marcove RC, Rosen G. Survival, prognosis, and therapeutic response in osteogenic sarcoma. The Memorial Hospital experience. Cancer 1992;69(03):698-708

24 Meister P, Konrad E, Lob G, Janka G, Keyl W, Stürz H. Osteosarcoma: histological evaluation and grading. Arch Orthop Trauma Surg 1979;94(02):91-98

25 Ohno T, Abe M, Tateishi A, Kako K, Miki H. Osteogenic sarcoma. A study of one hundred and thirty cases. J Bone Joint Surg Am 1975; 57(03):397-404

26 Min HS, Kang HG, Ro JY. Therapy related changes in osteosarcoma and Ewing sarcoma of bone. Open Pathol J 2009;3:99-105

27 Lucas DR, Kshirsagar MP, Biermann JS, et al. Histologic alterations from neoadjuvant chemotherapy in high-grade extremity soft tissue sarcoma: clinicopathological correlation. Oncologist 2008; 13(04):451-458

28 Jetley S, Jairajpuri ZS, Rana S, et al. Tumor histopathological response to neoadjuvant chemotherapy in bone sarcomas: a single-institutional experience. Int J Health Allied Sci 2020; 9:240-245 